\title{
Development of English Academic Writing Competence by Turkish Scholars
}

\author{
Louisa Buckingham \\ Sabancı University, Istanbul, Turkey
}

bucklj@gmail.com

\begin{abstract}
This study investigates how a group of 13 Turkish scholars from the humanities faculty of a prominent Turkish university perceive the development of their discipline-specific second language writing skills. Personal interviews were used to elicit data and excerpts from the interviews have been recorded in this paper. The acquisition strategies identified in the data reveal that the acquisition of scholarly writing expertise was an extended process of exploration of genre conventions, with a strong component of largely self-directed analysis of linguistic and organizational norms. The study considers how these strategies can be incorporated into a field study or portfolio-based academic writing program, with a view to training junior researchers to recognize the rhetorical, organizational, and linguistic characteristics of scholarly writing from their own discipline, and to monitor the development of their own writing competence.
\end{abstract}

Key words: Academic writing, second-language writing, publishing in a foreign language, language acquisition strategies, bilingualism, portfolio-based writing curriculum.

\section{Introduction}

The study of Non-Native Speakers' (NNS) scholarly writing ability is a topic of increasing interest for two main reasons. First, the presence of NNS students in Anglophone tertiary institutions has increased over the last decade, which places particular demands on faculty. Johns and Swales (2002), Paltridge (1997), and Jenkins, Jordan, and O'Weilland (1993) have also documented the growing trend to write doctoral dissertations in English, irrespective of whether the dissertation is submitted in an Anglophone country, which similarly imposes additional burdens on faculty and students. Jenkins et al. (1993) discussed the extra burden placed on supervisors by NNS doctoral candidates through the additional time spent correcting drafts (language and organizational problems) and support needed to assist NNS candidates in successfully completing the writing of their dissertations.

Material published as part of this publication, either on-line or in print, is copyrighted by the Informing Science Institute.

Permission to make digital or paper copy of part or all of these works for personal or classroom use is granted without fee provided that the copies are not made or distributed for profit or commercial advantage AND that copies 1) bear this notice in full and 2) give the full citation on the first page. It is permissible to abstract these works so long as credit is given. To copy in all other cases or to republish or to post on a server or to redistribute to lists requires specific permission and payment of a fee. Contact Publisher@InformingScience.org to request redistribution permission.
Second, whereas NNS publications in ostensibly international journals were once scarce (Swales, 1987), in recent years there has been a notable increase in NNS Research Article (RA) submissions to Anglophone journals. Johns and Swales (2002) have also observed a tendency across the disciplines of journals originally published in other languages to switch to an English-only policy. More recently, Mišak, Marušić, and 
Marušić (2005) have noted that in non-Anglophone countries journals are frequently founded with an English-only policy.

The imperative for academics to publish in English in international journals was confirmed by the Turkish scholars interviewed in this study (the interviewees remain anonymous and are referred to throughout as Respondent 1 [R1] etc.):

R7 "Universities require staff to write in English; there's no kudos for Turkish-written texts. Social Science Citation Index journals don't hold Turkish journals."

$\mathbf{R 3}$ "In order to exist in academia you have to publish in English, there's no alternative in the Social Sciences. There are no Turkish journals in the international journal citation index. I write in Turkish because I feel the responsibility to return something to my country."

The dominance of English in international research and education has led to discussions in the literature (Johns \& Swales, 2002; Mišak et al., 2005) on the pressure to 'exist internationally' through publishing in English, which leads to an evident skewing of research towards topics of global as opposed to local interest, and accords a natural advantage to Native Speaker (NS) researchers. While the first issue is beyond the scope of this paper, the perceived advantage of NS is of central concern to this study. It is indisputable that NS scholars enjoy certain linguistic privileges a priori, and the increase of research undertaken in English by NNS has raised issues of scholarly language requirements and editing responsibilities that were previously less acute. Nevertheless, as the plethora of NNS publications in all disciplines attests, many NNS scholars appear to compete on an equal footing with NS scholars. This study explores the experience of highly successful NNS scholars in developing Second Language (L2) academic writing competence with the purpose of identifying the strategies they consciously or unconsciously developed in order to pursue a competitive academic career of research and publication in English.

Although this study will make particular reference to publishing RAs in English, consideration is also given to the scholars' experience as doctoral students in light of the blurred distinction of writing genre (that is, scholarly or professional writing tends to begin earlier and is not always clearly distinguishable from writing one's doctoral thesis). The focus of the study is on how the writing competence of a scholar progresses from a level typical of doctoral students to the style and level of sophistication commonly found in professional scholarly writing. The discussion of the principal topics raised by the respondents leads to recommendations on how to support the writing development of junior researchers, and the proposal of concrete strategies for a selfdirected exploration of genre to refine scholarly writing skills and develop genre sensitivity.

The distinction between Ph.D. and RA writing has blurred due to the evolution of the article anthology thesis format, which enables students to publish during their studies. The advantages of the latter style are obvious and, in addition to the on-the-job training described by Dong (1998), junior researchers, in the words of Johns and Swales (2002, p.16), "establish a publication profile" early. However, it does present additional issues in the context of support to doctoral students with English for Academic Purposes (EAP); the monographic thesis is no longer the ultimate product, a genre unlike any other; instead students produce a series of publishable RAs. Johns and Swales (2002) have pointed to the hybridization and the resultant rhetorical complexities observed in the current doctoral dissertation format, as their survey revealed that a dissertation may display features of both types.

\section{Theoretical Background}

Previous research has identified areas of language difficulty in second language writing, for example Hinkel (2003) has described features of weak writing (commonly called vague, simple constructions) among NNS academics as being: overuse of be copula as the main verb, frequent 
use of vague nouns as well as public (e.g. admit, agree) and private verbs (e.g. feel, hope, realize). In an earlier study of NNS writing at the postgraduate level, Allison, Cooley, Lewkowicz, and Nunan (1998) discussed problems in organization on a macro-level of the thesis and on a micro-level of the paragraph, substantiation of arguments, strength of claims, as well as on the surface level of grammar and the mechanics of spelling, punctuation and bibliographic referencing. Shaw and Liu (1998) have described typical problem areas in undergraduate NNS writing. Although L2 writing problems are often ascribed to First Language (L1) interference, Shi (2002) and Hirose (2003) have also discussed the influence of L2 writing skills on L1 writing ability. These authors conclude that scholars who undertake the majority of their research in a second language (e.g. English) may find that their scholarly writing in their first language is influenced by second language writing norms.

The traditional NS - NNS dichotomy widely employed in academic research has been termed problematic (Connor, 2002; Flowerdew, 2000; Kubota \& Lehner, 2004; Swales, 2004) as it obscures individual developmental histories and suggests that the challenges of academic writing experienced by NNS are not experienced by NS (Gosden, 1992; Wood, 1997). Indeed, journal editors (Mišak et al., 2005) have observed that, at the level of a junior researcher, NS and NNS writing problems are strikingly similar with respect to areas such as organization and presentation of findings. Most Turkish academics may be categorized as NNS, but the disadvantages experienced by academics in less affluent countries (such as physical and material shortcomings, as summarized by Swales, 2004) are not present in the context of Turkey's top universities, which offer a teaching and learning environment on par with high-ranking western institutions. Possessing a highly sophisticated language competence, most Turkish scholars at these institutions would not fit neatly into the NNS category. Swales (2004) preferred the two-way distinctions of junior and senior researchers, and narrowly English proficient and broadly English proficient writers. Flowerdew (1999) underscored the value of further investigation into the experience of individual NNS scholars, ascertaining that their experiences can vary widely due to particular differences in linguistic and cultural backgrounds, and physical circumstances. This can also be appreciated in the individual accounts of writing skill development by the contributors to Belcher and Connor's (2001) study.

The 'genre-sensitizing' and field study approach to the teaching of discourse-specific scholarly writing has been explored by Swales (1987) and Hirvela (1997). Swales (1987) outlined methods in which a heterogeneous group of graduate students may be guided to explore different aspects of writing (for example, the use of citations) through interviews and text analysis, with the aim of sensitizing students to the strategies used by writers in the development of scholarly discourse. This type of 'field-study' approach to the teaching of academic writing, whereby students themselves "become ethnographers of the discipline", is further explored by Hirvela (1997) in his portfolio based curriculum which aims to create with a "student generated portrait of discourse communities' academic conventions" (p. 85) involving both surface-level grammatical practices and rhetorical conventions such as the use of metadiscourse. As Gosden (1995) has stipulated, a further longer term goal of this approach is to train junior scholars to become independent RA writers through the development of genre awareness combined with self-regulatory strategies.

\section{Method}

This paper loosely follows the studies undertaken by Flowerdew (1999) and Riaz (1997), based on data elicited from informants. The procedure is to a certain extent ethnographic, as the interviews were only loosely structured around pre-set interview questions asked to each respondent, and each interview evolved differently with further information elicited on experientially rich topics. 
Twenty five members of the Faculty of Arts and Social Sciences (junior and senior) were approached with the request that they be interviewed on the development of their professional writing ability. This faculty was selected as various studies concerning NNS academics in the sciences are documented in the literature (Dong, 1998; Flowerdew, 1999, 2000; Jenkins et al., 1993; Shaw, 1991; Swales, 1987; Zhu, 2004), whereas the arts has received lesser attention, possibly due to the prominence of research in the hard sciences. Moreover, it is widely believed that greater emphasis is placed on writing in the humanities, as writing is the principal expression of academic expertise. In addition, the nature of writing in the humanities appears more challenging than in the sciences. Casanave and Hubbard (1992) have reported that humanities and social science faculty place greater weight on the development of ideas, organizational issues, and appropriateness of vocabulary and style than science and technology faculty.

Thirteen faculty members representing the following subject areas agreed to be interviewed: Ottoman History, Anthropology, Cultural Studies, Economics, Conflict Resolution Studies, and Law. All had enjoyed a substantial part of their education in English (see Table 1). Although they did not come from bilingual families, all had attended a bilingual high school and some even had attended a bilingual primary school. The interviewees (four male, and nine female), all holding $\mathrm{Ph} . \mathrm{D}$. degrees, were aged between 30 and 60 and had been publishing in English for between two and eighteen years. Thus, their experience varied considerably due to changes in educational opportunities through the decades and the depth and breadth of their publishing experience. All had undertaken university studies in English at an English medium university in Turkey, and, with the exception of one person who completed his studies in Germany, all completed graduate studies in the United States, some remaining for over a decade. All respondents would correspond to Swales (2004)'s classification of senior researchers, broadly English proficient writers.

Table 1: Interviewees' academic background ( $N=13)$

\begin{tabular}{|l|l|}
\hline Education in English: & Number out of the 13 interviewees: \\
\hline Primary school: & 5 \\
\hline High school: & 11 \\
\hline Undergraduate studies: & 12 \\
\hline Graduate studies in the United States: & 12 \\
\hline Number of years publishing in English & Number out of the 13 interviewees: \\
\hline 1-5 years: & 5 \\
\hline 6-10 years: & 5 \\
\hline 11-20 years: & 3 \\
\hline
\end{tabular}

All interviewees conduct research in English, although the extent varies. Eleven respondents claim to do between 70-100\% of their professional reading and writing in English (of which, four claimed to work 100\% in English), while the percentage for the remaining two (Ottoman History experts) was naturally much lower at between $30 \%$ and $50 \%$. Publications in Turkish, when they existed, were downplayed (with the obvious exception of the Ottoman History scholars), which corresponds to findings in the literature (e.g. Swales, 2004).

A set of interview questions were developed (see Appendix), loosely based around the three basic stages of writing (planning, drafting, and revision), inviting respondents to reflect on conscious tactics they have employed, with a view to uncovering how they perceive their own development 
as professional second language writers, their relationship with English and Turkish, their personal approach to writing, and, as a result of their own developmental experience, the type of assistance or advice they offer (or claim to offer) peers and their own graduate students. Obviously, the data involve a degree of subjectivity, but this does not invalidate the findings; of central interest is precisely how individuals in this relatively homogeneous community of NNS professional writers view themselves.

Interviews of between 40-60 minutes were conducted in English in the private office of each faculty member, with responses to questions transcribed in the course of the discussion. A face-toface discussion was chosen as the most appropriate medium to collect data for this study, as the interview itself served as a medium for guided reflection. At times, a question would need reformulation before the respondent was able to deliver a detailed response. Such prompting would not have been possible if a questionnaire had been simply sent to each respondent for completion. Further, it was hoped that a personal interview-discussion approach would encourage the respondent to feel more at ease when asked to reveal details about his/her personal development of academic skills to a stranger

The questions varied from biographical data questions to open questions regarding the development of participants' experience as NNS writers. The questions mainly inquired into experience at the planning, formulating, and revising stages; however, additional questions concerning experience when submitting articles to journals were also included to incorporate the final step of the writing process. Following recommendations from Flowerdew (1999) on interview questioning techniques, a broad variety of questions types were used. Closed questions that received a positive response were followed by an open question asking the respondent to describe the relevant experience or provide reasons for the situation discussed. Some questions which received a negative answer when first posed, when phrased differently at a later stage in the interview were successful at eliciting experiences and examples (for instance, an interviewee denied making notes of particular formulations as model language, but later in the interview claimed that he tried to incorporate more unusual words, "sexy words", that he noticed from his readings into his own work, a practice which implies at least mental note-taking). As Flowerdew (1999) has discerned, the data obtained is subjective in nature and can merely be held as illustrative of certain experiences that NNS are known to undergo; the absence of a response from one respondent on a particular issue cannot be interpreted necessarily as a negative response, as factors such as the interview context, the formulation of the question, and the salience of a particular issue at that point in time potentially influence responses.

\section{Results}

From the testimonies transcribed, a series of recurring themes became apparent that serve as a guide for the ensuing discussion. What follows is a summary of these testimonies. Not all responses are included; rather, due to space restrictions, examples which are particularly illustrative of a tendency observed have been selected. The respondents' own voice is incorporated, as their experiences are rich with details and examples.

\section{Writing in English is Difficult}

All interviewees admitted that writing professionally in English involved difficulties. This is of interest as the majority of the respondents enjoyed a bilingual education system since their youth; nevertheless, writing in English did not come automatically and all interviewees described specific difficulties they experienced. Other than the basic issues of grammar, article use, and punctuation that almost all identified, three main issues were widely mentioned: the greater amount of time that composition requires in English (as opposed to NS), the perceived lack of sophistication 
in their use of language, and the related perceived need in the Humanities to write in an elaborate style.

R2 "English not a language that I can express myself in in a precise way. I feel that I don't have the finesse. English is my L3. But the more I write the more routine patterns and phrases I find."

$\mathbf{R 3}$ "Finding the right word takes a lot of time when working on an article, but this is the same as NS, NS do the same, just NNS need more time."

R5 "NNS need much more time than NS for the composition process. Often they spend their whole professional life in English but still need more help and time."

$\mathbf{R 8}$ "In the social sciences it is a disadvantage due to the type and amount of writing needing to be done. It is always difficult to express yourself - never like a native speaker. It is different from science where there are exact results; we need to express subtleties fluidly. Social scientists need to prove things through language. Maths is an international language; you can prove experiments in lab with maths, with the production of some product. In the social sciences you need a decent paper - you have to rely only on your paper and your ability to use language to convince the audience. There are NS also doing research at the same level - NS publish more easily when writing on the same topic."

R11 "We write slower, thinking time and the checking time is slower. Our vocabulary is less than NS. My biggest difficulty is vocabulary. If I use the same word in consecutive sentences then I need to use my thesaurus."

\section{Dissertation versus Research Article Writing}

In addition to the aforementioned writing difficulties of a general nature, the respondents also noted the greater challenge that RA writing presents compared to writing a doctoral dissertation. Particular discourse characteristics that respondents identified as differentiating Ph.D. and RA writing involved, for example, the priority of knowledge display in a dissertation, and knowledge 'packaging' (i.e. the importance of how knowledge is communicated) in a RA.

R8 "Graduate studies and professional writing are different things. A professional writer needs graduate studies writing experience as a base. Graduate writing is different because of the length of the research - you can be proud of your 360 footnotes. A dissertation is like a long drink whereas an article is like a shot - shorter, and more difficult than longer writing. 7000 words is much more difficult than 120,000 words. Professional writing means conciseness, limitations, precise expressions, limited space to express yourself. The audience is more critical; it's more difficult to publish than to pass your dissertation, there are many more factors involved. A Ph.D. is not a professional writing exercise; you still have to develop that over time."

R11 "Very different - as a grad student you are thinking about your ideas all the time and how to demonstrate what you know and not so much about how you are saying it. But when writing for journals I have to think of style and language - the most important things - how I say something. It is much more complex."

\section{Writing in the L1 is Difficult}

Echoing a tendency identified by Shi (2002), respondents note that, due to receiving all their education and professional training in English, they do not know how to write professionally in Turkish.

R1 "Writing in Turkish is an obstacle. All my education was in English and my knowledge of all terms is in English. I only know how to express these things in English." 
R4 "Turkish is difficult, reading and writing in Turkish is also difficult; I am more at home in English."

R5 "I often don't know how Turkish works, Turkish ways of doing things. I am trained in one way of writing, the English way. I am not aware of differences or how to do things in Turkish."

R8 "It is difficult to find the words in Turkish."

R11 "I am more confident in Turkish but objectively people say that my English is clearer, much better than my Turkish. My Turkish writing is confusing: it "smells" English and this is because I learnt to write professionally in English first."

\section{The Influence of L1 Texts on Writing in English}

The overriding opinion expressed by the respondents was that they did not perceive any L1 influence on their writing, not only due to lack of exposure to Turkish academic discourse, but also due to the perceived lack of professionalization and standardization of academic discourse in Turkish. Interestingly, only one person (R9) was able to identify organizational characteristics of Turkish writing that differed from English texts.

R1 "No, Turkish texts for economics are of a low level, we don't use them, we don't refer to Turkish journals. There are not too many economics publications in Turkish."

R3 "In Turkish there are no real academic journals in the social science field. The usual journal type is an intelligentsia, public journal, writing without citations. But Turkish will develop in the next decade."

R6 "English academic writing is better, more precise, pertinent. Academic writing in Turkish is often a translation of English customs. English for international publications is a natural choice. Ottoman Turkish is much richer for this field. Scholarly Turkish is artificial, has jargon and neologisms, borrows from English or other languages, revives old words in a different context."

R7 "Writing in Turkish I'm more self-conscious, it feels like a translation, and because of selfcensorship in Turkish. You have to take care of what you say, be on your guard. The social science tradition is not developed in Turkish, not sufficiently developed, it is still an imitation of the West, not necessarily a successful imitation."

R9 "Turkish has a very loose structure, several thesis statements are possible, also thesis statements appear at the end; rules are not always defined, it's more creative."

R13 "Publications in English tend to have more information on capturing different approaches and then situating yourself as a writer. Turkish is freer, old fashioned perhaps, where you just went on with your argument, you didn't have to describe the field and situate yourself. Turkish is full of impressions and thoughts, arguments, and on the way you might mention another author."

\section{Assistance from Advisors}

The respondents differed on the extent to which they received support from an advisor on their writing during their doctoral studies. Whereas some respondents stated that they received no assistance, or that their advisor did not possess the necessary skills to assist (R1), others described the assistance they received as being in the form of lower level support such as in punctuation, article use, and grammar (R10). Others (R9) said that help was offered on a discourse level in terms of organizational issues and expressing oneself effectively (R5; R13). The type of help received is important, as mere correction of articles, punctuation, and tense use does not necessarily contribute greatly to development of professional writing, although it does achieve formal accuracy. It is also apparent that the expertise and readiness of advisors to offer the help needed for the development of higher level skills cannot be taken for granted, and that it is incorrect to as- 
sume that during doctoral studies a student will undergo a form of 'cognitive apprenticeship' with his or her advisor. In the best of circumstances this may occur, but it seems more usual that the student has to rely on developing his/her own strategies.

R1 "My advisor was not a NS and did not give language help."

R4 "No, I learnt through exposure, passively."

R5 "I got feedback from tutors - how to express ideas in a more effective manner."

R8 "I received feedback from my advisor - punctuation, articles use, minor revisions. Colleagues can't always help."

R9 "From the tutor I had help with problems with syntax and organization of papers."

R10 "Just on papers in grad school. Just the usual language help."

R12 "I had two advisors in the economics department, both NS, but they didn't give feedback on language. It would be inappropriate, it wasn't their job; they were there to correct theoretical things, models, findings. I would find it patronizing if I were an advisor, I wouldn't do it."

R13 "My main mentor for my Ph.D. was someone who took the trouble to read everything and comment on things saying: there is a buried argument here, you need to foreground it, too many divergent things going on, what is the main question you are asking."

\section{Difficulties in Writing in English}

Almost all respondents noted a degree of dissatisfaction with their use of English in their professional writing. This varied from issues of formal correctness, such as article and punctuation use, and stylistic issues such as the use of passive voice and long sentences, to more complex areas such as tone, richness, and idiomaticity. The higher level features of language use were considered important to the respondents as, in their words, unlike science faculty, the work produced by social scientists and historians relies wholly on language, and therefore issues of complexity, richness of word choice, and tone of writing gain importance.

R1 "I still have difficulties with articles, punctuation, long sentences, organization of ideas sometimes; my language is not formal enough - I don't always know when to use daily language in writing. And getting the tone and force of a proposition right - I want to disagree or criticize something but I have to be very careful about how I do it, or I want to introduce something, an idea, and I have to be careful about how I phrase it."

R4 "At times I can't figure out nuances of meaning, and the dictionary doesn't help much. While revising my dissertation, I was aware of using very dry language, it was $90 \%$ correct grammar, but didn't feel good, like square expressions. And the appropriate tone is difficult."

R5 "When I look at NS writers, their style is different. I write in a very direct fashion. My writing is not that complex; I would like more complex persuasion and complex structures. I explain thoughts in two sentences where NS would be more concise... Word choice is necessary to express the exact idea instead of two to three words, for example, tectonic shift - they are words that capture it well, rather than big or large change."

$\mathbf{R 8}$ "Tone is sometimes a problem - maintaining a neutral objective style, generalizations are a problem - they shouldn't be too affirmative."

R10 "I have difficulties in using the appropriate tone and force when making propositions. In grad school I made statements that did not sound scholarly or academic, they were too direct or extreme, for example, the author does something excessively; it is difficult to determine the tone of criticism, I am too harsh, too argumentative... I learnt by reading others' writing and the feed- 
back from my supervisors helped me, it was like: do you really mean this? ... It is a disadvantage not being able to write in more striking ways about the topic. In my field, the style of writing is important to scholarship; it is not like writing about physics. I feel that I can't write as colorfully as NS academics."

\section{Using Texts as Models}

Explicit awareness of general conventions in the field and, in particular, the specific conventions and expectations of potential publishers seemed to be an important strategy of many respondents when aspiring to develop 'publishable' research, with many respondents claiming to have studied the organization and layout of published papers in journals of their subject area. Comments varied in the extent to which models were used; some benefited from looking for overall organizational characteristics, while others analyzed the discourse structure in detail.

R1 "Yes, I looked at the structure of articles. This may differ from one paper to the next but to get an idea of the general tendency, it's important."

R3 "I use models for organization; I often forget things, how things should be... Once I sent in an abstract before submitting an article. The editors came back and said the abstract wasn't what they wanted and I should look through back issues to copy style, use them for guidance. So I did that and changed my abstract, and they accepted it."

R8 “In 1996 after my Ph.D. I found it difficult to publish. I didn’t know how to write a proper article, I had difficulty and articles bounced back. I consulted journals to find articles on similar research topics and spent three hours taking notes on how they were structured, organized, constructed, how it was argued, how the author wrote it all up - I followed the example and the work was published immediately. The exercise showed me that there is a structure - it changes from field to field, genre to genre... It was my own analysis - I made a note of how many pages and paragraphs were devoted to each section. It was because of my own need to publish and write successfully that I learnt what to do, not because of some artificial requirement of a course assignment that said I had to write in a certain way - those things never helped me."

R10 "I read the journal articles, look for patterns, how they started, where they started, what they expanded on, what things are in the footnotes, in the endnotes."

R13 "It's only now as I start to review articles in journals that I start to dissect more, look at how they put it together; I'm more attentive to structures, before I was more attentive to ideas in each sentence. Now I take a step back and see the whole organization, now I am more conscious of what I enjoy."

\section{Noting Vocabulary and Expressions}

Almost all respondents could identify ways in which they used their exposure to language through their discipline-specific reading to enrich their own stock of vocabulary and expressions. This usually meant noting down expressions or formulations to use later in their own writing. Interestingly, although some respondents claimed they did not consciously note down words or expressions, in response to a different question they gave instances of how model texts from their discipline shaped their own language use in English. The comment voiced by several respondents that the acquisition of rich, discipline-appropriate discourse should be a lengthy process of assimilation involving noticing and remembering could possibly be due to the privileged position of these scholars with respect to the English language. Not all academics benefit from bilingual schooling and undergraduate education in addition to doctoral studies in the United States, a scenario which facilitates an assimilation process over many years. Instead, many are pressured to 
publish in English after receiving academic training in their L1, and thus have to develop the necessary accurate and expressive use of language over a more condensed period.

R2 "If you consciously read, you will encounter expressions, ways of saying things. I feel artificial using them at first but with correction I refine this skill."

$\mathbf{R 3}$ "A way to develop writing in English is to jot down phrases; it's difficult to say things like in sum, overall, in general, finally. I am so involved with ideas, struggling with the ideas, and this does not make the article reader-friendly, NS help you with this. Ideas are in the raw. I have made lists although I felt like a nerd. I think I should just keep things in mind."

R5 "I always studied how professional writers formulate their ideas. I would make notes on cards of nicely formulated expressions and phrases - I'd write them down and used them."

R6 "I was always an avid dictionary reader from cover to cover - I'd take notes of words or idioms and find parallels in other languages."

R8 "I try to use alternative words, I look for sexier words - like for explore, elucidate. But it is a process that can also lead to wrong word use. It needs care and I have to always check in manuals. But I don't make notes of useful expressions. Acquiring native-like writing expressions should be a process of long assimilation. There's no formula in it."

R12 "I make mental notes of how to say things and I'm conscious of repeating things that I've seen in texts."

\section{Mixing Languages}

This topic was included to probe into the complex relationship between native and non native language use. Whereas language learners are often entreated to 'think in English', there is evidence that suggests that combined use of languages assists complex cognitive tasks (Belcher \& Connor, 2001; Dong, 1998; Woodall, 2002). Furthermore, in the case of academics working with material in their native language (interview data, historical records, official documents etc.), as one would expect in the case of social scientists, historians, and anthropologists, the incorporation of both languages into the task of planning and writing seems logical. From the respondents' experience, it would seem that even with a sophisticated level of bilingualism, languages cannot be compartmentalized, and the achievement of cognitively complex tasks is aided by summoning all language competence at one's disposal.

R1 "Usually the writing is in English, it is mixed in my head so certain things are always in English or Turkish."

R2 "I don't mix languages; if the article is in one language then I think and plan in that language."

R3 "Yes, all the time. Annotations and exclamations are in Turkish. I often use a mixture of the languages to attract attention."

R4 "I think in English though. In spoken language I am careful not to mix but written language becomes a blend, a mixture."

R6 "Depends on the sources -then I mix languages; but the outline I do in English and the notes."

R10 "The exception is when I write about a Turkish text, then I write sections or notes in Turkish. Otherwise I don't really mix them."

R11 "In the Conflict Resolution field all concepts are from English; it's very difficult to transfer to a Turkish speaker, then I have to mix the words. When writing in Turkish I do mix, my mind starts doing it in English and I have to find a replacement before putting it into words, for exam- 
ple, reconciliation, most of the time we can't find a direct translation so I have to look for a word from Ottoman Turkish."

R12 "If I don't know an English word, just to rush, I switch to Turkish; otherwise I stick to English. Terms in economics are in English; I don't know the Turkish.”

\section{Introduction and Conclusion: The most Difficult Sections}

Questions were phrased to elicit the respondents' experience of writing within the organizational constraints of a RA, each part of the paper characterized by particular content and organization. Almost all interviewees stated that they began writing in the middle sections, leaving the Introduction and Conclusion till last (in contrast, two interviewees began with the Introduction). The Introduction and Conclusion sections were generally viewed as more challenging, due to the need to express ideas succinctly and address the audience convincingly. This was particularly true in the economics field (R1), where the body of the text tends to be 'equation dominated'.

R1 "The main text is full of math equations, explanations of models, deriving the results, it has a clear and predictable structure and we are very limited in our language use - this is very predictable and we can't vary this - if I vary it I will be criticized. This is not so in the Introduction and Conclusion, and these sections are more difficult as I can write different things but I have to be brief; the first paragraph is catchy, the second paragraph explains the model. My language has to be very plain except for the Introduction and the Conclusion."

$\mathbf{R 3}$ "I start with the body, a little on the Introduction, the Conclusion is last, and I sometimes use copy-paste to move between the Introduction and the Conclusion. I am aware of this relationship between them."

R7 "The Introduction is the most challenging section; I have to care about succinct expressions, audience concerns."

$\mathbf{R} 10$ "Most difficult section is the Introduction. The whole formulation of the Introduction is difficult."

\section{Colleagues and Peer Review}

Peer review (whether with the help of NS or NNS) was generally viewed as a way not only to check the clarity and style of one's writing, but by some it was also seen as a constructive way to heighten one's awareness of problematic language areas. On the other hand, two respondents felt that giving feedback on language use would be inappropriate; review by peers is therefore not always seen as a channel for improving language use.

R3 "My peers edit my work - give me language help. In the field of law there are too many irregularities, you can't guess, you need NS' help. In articles, translations of the informants' speech sound awkward and I need help to make it more natural."

R7 "I share work with other people... and I read unfinished manuscripts, draft articles and comment on them. It is a good way of thinking about what I do. It reminds me of how hard it is - the gap between the draft and final publication."

R9 "I worked as a writing tutor during my doctorate; this helped in terms of learning from other work from both NS and NNS: I see my own mistakes in style and organization."

R12 "I don't give feedback on language: it's unfair, inappropriate; language is of secondary importance." 


\section{Journals and Peer Review}

Feedback on journal submissions was considered to be very helpful in terms of language development:

R1 "I see corrections from peers or editors and I learn from them."

R10 "Comments from reviewers are very useful. My own writing is too compact; it is difficult to get all thought processes on paper, connectors are necessary. And I saw this because reviewers seemed to miss points I was trying to make, points I had to explain, to expand on."

A related issue concerns whether NNS should be permitted to retain certain features of their style that identify them as using a variety of global English. Flowerdew (2001, p. 140) has documented a degree of openness on behalf of certain journal editors to accept 'nativized varieties of writing', which include use of language or rhetorical patterns that may be classed as non-standard, but which constitute a recognized norm within a particular language community using English as its language of professional research and communication. When respondents were asked whether they would prefer to have all examples of so-called 'non-standard' language corrected, the responses were in favor, perceiving the retention of non-standard features as potentially limiting their readership.

R3 "I had a hard time about the changes needed once. The director of a journal told the editor to leave some errors, non-standard features should be left, so although you gain space to be oneself, you compromise the intelligibility of a paper. I am self-conscious; I need to go over it in perfect US English. The whole purpose of the paper is a painful ordeal, then suddenly to be told you are free to use language as you want is a false freedom because the structure is very rigid, set, established. You want to reach people, not to lose people along the way; the average publication is read by seven people, I don't want to limit readership, the journal is a channel to find people who share your same interests, I don't want to jeopardize this."

R4 "I like the language I use to be standardized. But I like also playing with words, and I would want to indicate this. I like language standardized; when I read NNS writing, some things seem odd, and this can lead to misunderstandings, prefer a loose personalized style and language."

\section{Improving Writing through Writing (and Reading)}

Finally, a key point consistently identified by the majority of the interviewees concerned the need to 'read to write' and for continual writing practice. In addition, reading widely was seen as making a key contribution to broadening vocabulary and the attainment of a greater fluidity of expression through obtaining a stock of functional expressions (R12). Participants in Belcher and Connor's (2001) reflective study on L2 writing development also underscore the importance of broad exposure to a variety of text types.

R2 "Write as much as possible - don't be shy, the correction by NS is useful, but don't emulate a model; the creativity of your own style is important."

$\mathbf{R 3}$ "The best thing to do is to just write, read a lot and write a lot as well. Writing a lot improves writing."

R4 "Get feedback, practice writing as much as possible, and do corrections of papers."

R5 "Practice, write drafts and share the process."

R7 "Academic writing often isn't good writing. I read a lot of material from outside the field, literature. Detail and texture of language is important. Academic writing is so much concerned with the theory debate and other voices. Read. Students have a hard time reading. The preparation of 
students is insufficient; students don't read outside the field. By definition writing improves because of better models."

R8 "I developed my ability through reading in the field."

R3 "If you don't write it gets worse - practice is necessary."

R12 "Reading influences how you do things. For example, at the end of the Introduction people say: the study will discuss; the first section investigates; subsequently I will show... I notice these things... I read a lot in English, novels and newspapers."

\section{Discussion}

This section discusses the information elicited from respondents under two main themes: writing difficulties experienced by this group of scholars, and the assistance that was available them throughout the development of their discipline-specific writing expertise.

\section{Difficulties in Writing in English and Strategies to Support One's Writing Development}

Contrary to initial expectations, it appears that even this group of scholars perceives disadvantages in their need to write professionally in a foreign language. All respondents were able to identify personal problem areas, many of which, like concerns with surface level issues such as articles and punctuation, were shared (sections "Writing in English is Difficult" and "Difficulties in Writing in English"). Some respondents also discussed their desire to say things in a "nicer", more persuasive or succinct way, evidence that underscores the importance of style in their field, and explains why sections such as the Introduction, Discussion or Conclusion are perceived as more difficult, requiring as they do greater socio-pragmatic awareness of the context of the research community in which the study is situated (sections "Introductions and Conclusions" and "Journals and Peer Review"). As other authors have noted, such concerns reflect equally well those of junior NS writers (Gosden, 1992; Mišak et al., 2005; Swales, 2004; Wood, 1997). However, at the level of the experienced scholar, the authors point to problem areas typical for NNS such as the presentation of the study design, the different types of narrative in the Introduction, Methods, Results, Discussion format, as well as knowledge of the specificities of the required language genre (these closely reflect the shortcomings noted by Allison et al., 1998). The majority of faculty identified similar strategies (unconscious or conscious) to support their development as scholarly writers, implemented at their own initiative in an ad hoc manner and involving the emulation of writing in their field. This varied from copying and making mental notes of useful language, to studying model texts for organization and style (sections "Using Texts as Models" and "Noting Vocabulary and Expressions").

These respondents did not perceive any influence of L1 norms, with the majority professing not to be aware of either the characteristics of scholarly writing in Turkish or the existence of differences (section "The Influence on L1 Texts on Writing in English"). This provides evidence of the complexities of labeling NNS in a pedagogic context according to nationality, encouraging a static view of culture criticized by Kubota and Lehner (2004) and Connor (2002) that ignores the rhetorical plurality deriving from cultural hybridity. The majority of these respondents confessed that their scholarly identity was expressed exclusively in the English language, and that they would not be able to perform professionally in Turkish. One respondent even described her formal written Turkish being criticized for displaying overtly English characteristics. It is significant that, other than an over-use of passive structures and long sentences, respondents did not feel that Turkish influenced their writing in English. 


\section{Assistance from Advisors during Doctoral Studies and Use of Peer Review}

Contrary to expectations, many of the interviewees claimed not to have received support that might be classified as 'cognitive mentoring' (as described by Belcher, 1994) from their supervisors in the United States. This was due either to the supervisor supposedly not being in a position to offer such feedback, not being a NS (although this is not a prerequisite), or to perceived lack of appropriateness (section "Assistance from Advisors"). Where language feedback was received, this was generally in the form of surface-level corrections, with only two respondents receiving feedback on organization and language use. With regard to peer feedback on current research, two maintained that they frequently consulted their NS peers either for feedback on terminology or for proofreading while drafting a research article, while others claimed they gave and received feedback with regard to content only, as comments concerning language would be inappropriate (section "Colleagues and Peer Review".

Belcher (1994) identified two main weaknesses of the cognitive mentoring model; first, she maintains that this model assumes that "senior researchers, for example, automatically 'model' and 'coach', yet these roles seem not to be intuitive to some of the advisors of my students." The experience of these respondents was mixed, but the majority responded negatively to questions that attempted to elicit to what extent the interviewees enjoyed a 'cognitive mentoring' relationship with their supervisors (section "Colleagues and Peer Review"). Their testimonies support Belcher's assertion that advisors do not necessarily possess the necessary awareness and skills to take on such a role. Secondly, Belcher (1994) also stipulated that this model centers on the supervisor-student relationship at the expense of the wider disciplinary community, an important consideration due to the increasing pressure on students to publish during the doctoral program. Being a 'peripheral participant' of the discourse community involves a higher degree of self-directed integration and would presuppose a more dynamic integration model than the narrowly conceived cognitive apprenticeship model.

In light of such findings, it would seem that reliance on supervisor mentoring or peer support is not realistic. One may even question the suitability of these scholars to provide such mentoring to their own doctoral students, considering they neither benefited from the cognitive apprenticeship experience with their own advisor nor did they necessarily receive systematic feedback on surface-level language issues. Some respondents considered such language mentoring inappropriate, a view echoed in the faculty survey results of Allison et al. (1998), and assistance from a writing center seems an option preferred by faculty for their own NNS students. Finally, these responses appear to underline the need, expressed by Swales (2004) and Mišak et al. (2005), for explicit support to be provided by editorial boards of international journals in the form of peer editing assistance and publishing and editing workshops, so that the requirement for sophisticated NS language competence in English does not prevent the acceptance of otherwise worthy papers. It is significant that the respondents in this study responded positively to the very specific feedback received on their manuscript submissions to journals from peer reviewers (section "Journals and Peer Review").

\section{Practical Implications}

The following paragraphs discuss the type of assistance that a writing center may offer to support graduate students and junior researchers in their dissertation and RA writing. This proposal is based on the genre-driven approach to academic writing instruction. As the discourse type that is the object of teaching emanates from distinct discourse communities, it seems sensible to suggest that any process of acquisition of such norms should begin with an exploration and analysis of the target community's discourse use. Hyland (2002) conceded that the task of arriving at an accurate 
linguistic and discursive description of such contexts is laborious, but he argued that it is precisely "this research that makes both our teaching effective and our practice professional."

Shaw (1991) has addressed the question of who should be responsible for teaching disciplinespecific writing skills. EAP teachers, those usually responsible, are not a part of such communities and are hardly in a position to familiarize themselves intimately with the specific genres of each university discipline, while members of the target discourse community are themselves rarely in a position to understand the NNS students' difficulties and appropriately develop teaching strategies. Shaw is supportive of student-centered exploration, that is, a curriculum based on the strategies that NNS instinctively employ (broadly described as exploring, noticing and describing). In such a context, the EAP teacher's role would be to provide the guidance and the framework for students themselves to decipher the characteristics of discipline-specific writing to arrive at their own understanding of discourse customs. The findings in this study suggest that this self-directed approach is one that successful NNS writers intuitively undertake. The responses elicited from this group of Turkish scholars (sections "Using Texts as Models", "Noting Vocabulary and Expressions", and "Introductions and Conclusions") reveal that strategies such as identifying 'appropriate' formulations and vocabulary, and analyzing the organizational characteristics typical for discipline-specific discourse are found to be particularly helpful.

The respondents in this study have also reiterated the need for practice ("write as much as possible") (section "Improving Writing through Writing"), specifically of sections of a paper which prove more challenging than others, such as Introductions and Conclusion (section "Introductions and Conclusions"). An individualized, portfolio-based approach to writing development, such as that proposed by Hirvela (1997) enables NNS junior scholars to develop discourse awareness and the self-regulatory strategies which serve to sharpen their ability to monitor and evaluate their writing. In the words of Hirvela (1997, p.89), a portfolio approach serves as "primarily an analytic tool that allows students to collect and reflect upon the results of their examinations of, and attempts to produce, the field-specific conventions of their chosen discourse communities."

Three types of information are recorded in the portfolio: firstly, students record their observations of disciplinary customs (through a rhetorical analysis of discipline-specific texts, a comparison of journal editorial requirements, and interviews with faculty who produce such texts); secondly, students reflect on the meaning and value of these data; and finally, students position them themselves, deciding to what extent they aspire to imitate them and to what extent these customs will help them develop their own writer's voice. This metacognitive awareness of one's own location in relation to genres (Ramanathan \& Kaplan, 2000) constituted an important part of the learning process of the respondents of this study, some of whom expressed the need to internalize the 'accepted' discourse style concomitant with the desire to retain and develop a personal style and voice, provided it was considered grammatically 'correct' (section "Journals and Peer Review").

\section{Conclusion}

The results from this study suggest that despite receiving an unusually high level of exposure to formal English through a largely bilingual education, this group of 13 Turkish scholars still perceived significant linguistic difficulties in developing their L2 scholarly writing abilities. The data collected reveal that, for most, acquiring their present level of writing expertise was a process of exploration of genre conventions, with a strong component of largely self-directed analysis of linguistic and organizational norms. The 'apprenticeship' period experienced as a graduate student did not necessarily prepare these scholars for professional research publication. Most view this as a separate competence that they acquired independently after completing their doctoral dissertation. The data collected were elicited through interviews and are thus subjective in nature, but they nevertheless shed light on what is usually a long-term, private process of skill development. Of future interest would be an investigation combining this reflective approach with an 
analysis of actual texts produced by scholars at different points of their development. Further, this study does not address how Turkish academicians in less privileged Turkish research environments develop the level of scholarly writing competence in English required by international journals.

\section{References}

Allison, D., Cooley, L., Lewkowicz, J., \& Nunan, D. (1998). Dissertation writing in action: The development of a dissertation writing support program for ESL graduate research students. English for Specific Purposes, 17(2), 199-217.

Belcher, D. (1994). The apprenticeship approach to advanced academic literacy: Graduate students and their mentors. English for Specific Purposes, 13, 23-34.

Belcher, D., \& Connor, U. (Eds.) (2001). Reflections on multiliterate lives. Clevedon: Multilingual Matters.

Casanave, C. P., \& Hubbard, P. (1992). The writing assignments and writing problems of doctoral students: Faculty perceptions, pedagogical issues, and needed research. English for Specific Purposes, 11, 33-49.

Connor, U. (2002). New directions in contrastive rhetoric. TESOL Quarterly, 36(4), 493-510.

Dong, Y. R. (1998). Non-native graduate students' thesis/dissertation writing in science: Self-reports by students and their advisors from two U.S. institutions. English for Specific Purposes, 17(4), 369-390.

Hinkel, E. (2003). Simplicity without elegance: Features of sentences in L1 and L2 academic texts. TESOL Quarterly, 37(2), 275-301.

Flowerdew, J. (1999). Problems in writing for scholarly publication in English: The case of Hong Kong. Journal of Second Language Writing, 3, 243-264.

Flowerdew, J. (2000). Discourse community, legitimate peripheral participation, and the nonnativeEnglish-speaking scholar. TESOL Quarterly, 34(1), 127-149.

Flowerdew, J. (2001). Attitudes of journal editors to non-native speaker contributions. TESOL Quarterly, $35(1), 121-149$.

Gosden, H. (1992). Research writing and NNSs: From the editors. Journal of Second Language Writing, 1(2), 123-139.

Gosden, H. (1995). Success in research article writing: A social constructionist perspective. English for Specific Purposes, 14(1), 37-57.

Hirvela, A. (1997). Disciplinary portfolios and EAP writing instruction. English for Specific Purposes, 16, 83-100.

Hirose, K. (2003). Comparing L1 and L2 organizational patterns in the argumentative writing of Japanese EFL students. Journal of Second Language Writing, 12, 181-209.

Hyland, K. (2002). Specificity revisited: How far should we go now? English for Specific Purposes, 21, $385-395$.

Jenkins, S., Jordan, M. K., \& O'Weilland, P. (1993). The role of writing in graduate engineering education: A survey of faculty beliefs and practices. English for Specific Purposes, 12, 51-67.

Kubota, R., \& Lehner, A. (2004). Toward critical contrastive rhetoric. Journal of Second Language Writing, 13, 7-27.

Johns, A. M., \& Swales, J. M. (2002). Literacy and disciplinary practices: Opening and closing perspectives. Journal of English for Academic Purposes 1, 13-28

Mišak, A., Marušić, M., \& Marušić, A. (2005). Manuscript editing as a way of teaching academic writing: Experience from a small scientific journal. Journal of Second Language Writing, 14, 122-131. 
Paltridge, B. (1997). Thesis and dissertation writing: Preparing ESL students for research. English for Specific Purposes, 16(1), 61-70.

Ramanathan, V., \& Kaplan, R. B. (2000). Genres, authors, discourse communities: Theory and application for (L1 and) L2 writing instructors. Journal of Second Language Writing, 9(2), 171-191.

Riaz, A. (1997). Acquiring disciplinary literacy: A social-cognitive analysis of text production and learning among Iranian graduate students of education. Journal of Second Language Writing, 6(2), 105-137.

Shaw, P. (1991). Science research students' composing processes. English for Specific Purposes, 10, 189206.

Shaw, P., \& Liu, E. T. (1998). What develops in the development of second-language writing? Applied Linguistics 19(2), 225-254.

Shi, L. (2002). How Western-trained Chinese TESOL professionals publish in their home environment. TESOL Quarterly, 36(4), 625-634.

Swales, J. (1987). Utilizing the literatures in teaching a research paper. TESOL Quarterly, 31(1), 41-68.

Swales, J. (2004). Research genres. Cambridge: Cambridge University Press.

Wood, A. (1997). International scientific English: Some thoughts on science, language and ownership. Science Tribune. Retrieved, November 13, 2006, from

http://www.tribunes.com/tribune/art971woodshtm/.

Woodall, B. A. (2002). Language switching: Using the first language while writing in the second language. Journal of Second Language Writing, 11, 7-28.

Zhu, W. (2004). Faculty views on the importance of writing, the nature of academic writing, and teaching and responding to writing in the disciplines. Journal of Second Language Writing, 13, $29-48$.

\section{Appendix: Questionnaire}

\section{Background in professional writing in the English language}

1. Did you receive your schooling/ university education in English?

2. In what language do you do the majority of your reading of academic texts?

3. In what language do you do the majority of your writing of academic texts?

4. For how many years (approx.) have you been publishing in English?

5. Is the need to publish in English an obstacle or a disadvantage? In what way?

6. Did you receive any help as you began to write scientific studies in English? Can you describe it?

7. Did you use any texts as models? In what way?

8. When you think back to your early years writing professionally in English, what were your main difficulties?

9. What differences have you noticed between style and organization in professional writing in Turkish and English in your field?

\section{Planning your work}

1. When planning a piece of research, or when planning a text, which language did you use? Did you mix languages? If yes, does it help or hinder you?

2. Have you used published texts from your discipline as a model while planning?

3. Are you able to describe any procedure you follow to when preparing to write a paper? 


\section{Formulating in English}

1. Have you ever done anything to help yourself formulate well-formed expressions in English?

- make notes of typical or useful phrases?

- Make lists of typical or useful vocabulary

- Copy out sections of text to use as a model

- In what way can your L1 help / hinder you?

2. Did you ever write sections of text in Turkish and then translate?

3. How many drafts do you do?

4. Which section is most difficult? Why is this?

\section{Revision}

1. What strategies did you use to revise your work for language errors?

2. What strategies did you use to revise the organization of your work?

3. Did you ask native speaker/ non native speaker peers to help revise your work?

4. Do you revise the work of your colleagues for questions of language and organization?

5. What difficulties do you notice in your own and your colleagues' work with respect to language use, style, and organization?

Advice to young non native speaker researchers / academics / new faculty

1. How can young writers help bridge the gap between writing for their own graduate studies and professional writing?

2. How can young faculty become more efficient and effective writers in their discipline?

Feedback from journal reviewers

1. Can you describe the sort of feedback you have received from reviewers (or that you have given as a reviewer)?

\section{Biography}

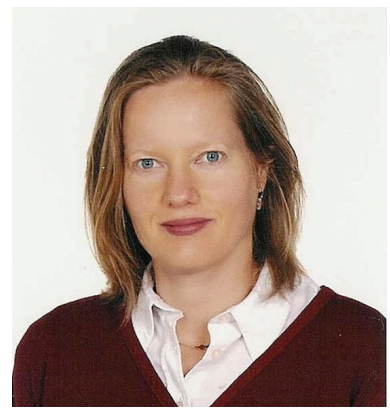

Louisa Buckingham is currently working towards a Ph.D in Spanish linguistics at the University of Granada, Spain. Her research interests include phraseology, second language writing acquisition, and language teaching. She has worked at Tuzla University (Bosnia), and Sabanc1 University (Turkey). She has also worked on teacher training programs for the School for International Training (US). 